\title{
The Study of the Effect of Titanium Dioxide - Surfactant Compound on Cefoperazone Treatment
}

\author{
LIU ZHI-bin ${ }^{1}$ \\ School of Food Engineering,Haerbin University of Commerce,Haerbin 150076,China
}

\begin{abstract}
Keywords: $\mathrm{TiO}_{2}$; surfactant; hexadecyltrimethylammonium bromide; cefoperazone
Abstract:efoperazone wastewater's composition is complex,of high COD, biodegradability is relatively poor, while $\mathrm{TiO} 2$ photocatalytic oxidation method is of high efficiency, safe, non-toxic and simple to operate, which can be used as a treatment method. The effect of hexadecyltrimethylammonium bromide $(\mathrm{CTAB})$ on the photocatalytic oxidation of $\mathrm{TiO} 2$ was also discussed. The $\mathrm{TiO} 2$ photocatalyst was investigated by sol-gel method. The $\mathrm{TiO} 2$ photocatalyst was coated with CTAB, and the dosing amount was $5 \%$. Treating cefoperazone as the target degradation products and the degradation rate of cefoperazone was determined by the change of COD value. The effects of photocatalyst dosage, light time, $\mathrm{pH}$ and other factors on the photocatalytic activity were investigated in this experiment. The results showed that the photocatalytic degradation efficiency was the highest when the dosage of TiO2-CTAB was $0.12 \mathrm{~g}$, the irradiation time was $5 \mathrm{~h}$ and $\mathrm{pH}$ was 7 . The degradation rate of cefoperazone antibiotic wastewater was $95.1 \%$ with the best experimental solution.
\end{abstract}

\section{Introduction}

The study about Antibiotic wastewater has been reported in the last twenty years.Photocatalytic degration of cefoperazone with Titanium Dioxide - Surfactant has not been previously investigated. We have researched the effect of Titanium Dioxide - Surfactant on photocatalytic degration of cefoperazone in water.

\section{Apparatus}

Electronic balance(FA604B) produced by Bejing satrious corporation.PH meter(PHS-3C ) produced by shanghai spectral corporation.Electric vacuum drying oven produced by shanghai yiheng corporation. Muffle furnace produced by tianjin zhonghuan experiment corporation.Vacuum pump produced by Henan province yuhua corporation.

\section{Reagent and materials}

Sodium hydroxide(AR); hydrochloric acid(AR);CTAB(AR);phenanthrolime(AR);ferrous sulfate(AR); glacial acetic acid(AR);tetra-n-butyl titanate(AR);mercuric sulfate(AR);potassium dichromate(AR);ammonium ferrous sulfate(AR);absolute ethyl alcohol(AR);nitric acid(AR);(The reagent were produced by Tianjin kemiou chemical corporation).Cefoperazone sodium sulbactam(Harbin Pharmaceutical Group Pharmaceutical Factory)

\section{Experimental section}

The COD of cefoperazone solution has been determined.The method is putting water and cefoperazone solution into digestion tank,adding appropriate mercuric sulfate,adding $5 \mathrm{ml}$ potassium dichromate and $5 \mathrm{ml}$ sulphuric acid-silver sulfate,putting into microwave digester,adding ferrous metal indicator,titrating ammonium ferrous sulfate.Computing the value of COD.

Weighing appropriate amount $\mathrm{TiO}_{2}-\mathrm{CTAB}$ and $\mathrm{TiO}_{2}$ to cefoperazone solution of $0.1 \mathrm{~g} / \mathrm{L}$.Putting ultraviolet lamp to illumination.Computing the value of COD.Computing the degradation rate. 


\section{Results and Discussion}

Orthogonal experimental factors are in the following table 1

tablel experimental factors

\begin{tabular}{cccc}
\hline level & $\begin{array}{c}\text { A } \\
\text { dosage/g }\end{array}$ & $\begin{array}{c}\text { B } \\
\text { light } \\
\text { application } \\
\text { time/h }\end{array}$ & $\begin{array}{c}\mathrm{C} \\
\mathrm{pH}\end{array}$ \\
\hline 1 & 0.08 & 3.5 & 7 \\
2 & 0.1 & 4 & 6 \\
3 & 0.12 & 4.5 & 5 \\
4 & 0.14 & 5 & 4 \\
\hline
\end{tabular}

Selection of orthogonal tables

Table 2 three factors and four levels

\begin{tabular}{|c|ccccc|c|c|}
\hline $\begin{array}{c}\text { experi } \\
\text { ment }\end{array}$ & $\mathrm{A}$ & $\mathrm{B}$ & $\begin{array}{c}\text { hollo } \\
\mathrm{W}\end{array}$ & $\mathrm{C}$ & $\begin{array}{c}\text { hollo } \\
\mathrm{W}\end{array}$ & plan & $\begin{array}{c}\text { degradat } \\
\text { ion } \\
\text { rate./\% }\end{array}$ \\
\hline 1 & 1 & 1 & 1 & 1 & 1 & $\mathrm{~A}_{1} \mathrm{~B}_{1} \mathrm{C}_{1}$ & 72.8 \\
2 & 1 & 2 & 2 & 2 & 2 & $\mathrm{~A}_{1} \mathrm{~B}_{2} \mathrm{C}_{2}$ & 72.1 \\
3 & 1 & 3 & 3 & 3 & 3 & $\mathrm{~A}_{1} \mathrm{~B}_{3} \mathrm{C}_{3}$ & 71.3 \\
4 & 1 & 4 & 4 & 4 & 4 & $\mathrm{~A}_{1} \mathrm{~B}_{4} \mathrm{C}_{4}$ & 69.8 \\
5 & 2 & 1 & 2 & 3 & 4 & $\mathrm{~A}_{2} \mathrm{~B}_{1} \mathrm{C}_{3}$ & 81.1 \\
6 & 2 & 2 & 1 & 4 & 3 & $\mathrm{~A}_{2} \mathrm{~B}_{2} \mathrm{C}_{4}$ & 80.4 \\
7 & 2 & 3 & 4 & 1 & 2 & $\mathrm{~A}_{2} \mathrm{~B}_{3} \mathrm{C}_{1}$ & 82.3 \\
8 & 2 & 4 & 3 & 2 & 1 & $\mathrm{~A}_{2} \mathrm{~B}_{4} \mathrm{C}_{2}$ & 82.9 \\
9 & 3 & 1 & 3 & 4 & 2 & $\mathrm{~A}_{3} \mathrm{~B}_{1} \mathrm{C}_{4}$ & 89.9 \\
10 & 3 & 2 & 4 & 3 & 1 & $\mathrm{~A}_{3} \mathrm{~B}_{2} \mathrm{C}_{3}$ & 92.4 \\
11 & 3 & 3 & 1 & 2 & 4 & $\mathrm{~A}_{3} \mathrm{~B}_{3} \mathrm{C}_{2}$ & 94.3 \\
12 & 3 & 4 & 2 & 1 & 3 & $\mathrm{~A}_{3} \mathrm{~B}_{4} \mathrm{C}_{1}$ & 95.1 \\
13 & 4 & 1 & 4 & 2 & 3 & $\mathrm{~A}_{4} \mathrm{~B}_{1} \mathrm{C}_{2}$ & 81.6 \\
14 & 4 & 2 & 3 & 1 & 4 & $\mathrm{~A}_{4} \mathrm{~B}_{2} \mathrm{C}_{1}$ & 83.4 \\
15 & 4 & 3 & 2 & 4 & 1 & $\mathrm{~A}_{4} \mathrm{~B}_{3} \mathrm{C}_{4}$ & 82.6 \\
16 & 4 & 4 & 1 & 3 & 2 & $\mathrm{~A}_{4} \mathrm{~B}_{4} \mathrm{C}_{3}$ & 81.2 \\
\hline
\end{tabular}

The range analysis of the result is in table 3

Table 3 range analysis

\begin{tabular}{|c|ccccc|}
\hline & A & B & C & D & E \\
\hline $\mathrm{I}_{\mathrm{j}}$ & 286 & 325.4 & 328.7 & 333.6 & 330.7 \\
$\mathrm{II}_{\mathrm{j}}$ & 326.7 & 328.3 & 330.9 & 330.9 & 325.5 \\
$\mathrm{III}_{\mathrm{j}}$ & 371.7 & 330.5 & 327.5 & 326 & 328.4 \\
$\mathrm{IV}_{\mathrm{j}}$ & 328.8 & 329 & 326.1 & 322.7 & 328.6 \\
$\mathrm{R}_{\mathrm{j}}$ & 85.7 & 5.1 & 4.8 & 10.9 & 5.2 \\
\hline
\end{tabular}




\section{The result of Orthogonal experiment}

We can investigated that the order of the three factors is $A>D>B>$ hollow. The best experimental scheme is $\mathrm{A}_{3} \mathrm{~B}_{4} \mathrm{C}_{1}$ : The dosage of $\mathrm{TiO}_{2}-\mathrm{CTAB}$ is $0.12 \mathrm{~g}$, light application time is $5 \mathrm{~h}$, The value of $\mathrm{pH}$ is 7.

Conclusion

Photocatalytic degradation of cefoperazone has been carried up, we have conclusion that: (1) Single factor experiment of $\mathrm{TiO}_{2}-\mathrm{CTAB}$ for cefoperazone indicated that the best dosage of $\mathrm{TiO}_{2}-\mathrm{CTAB}$ is $0.1 \mathrm{~g}$.

(2) Single factor experiment of $\mathrm{pH}$ for cefoperazone indicated that the best value is 7 .

(3) Single factor experiment of time for cefoperazone indicated that the best time is $4 \mathrm{~h}$.

(4) Single factor experiment of $\mathrm{TiO}_{2}-\mathrm{CTAB}$ for cefoperazone indicated that the dosage of photocatalyst is better than time and $\mathrm{pH}$.

(5) Orthogonal experimental results indicated the best programme is :the dosage of $\mathrm{TiO}_{2}-\mathrm{CTAB}$ is 0 . $12 \mathrm{~g}$, the light time is $5 \mathrm{~h}$, the best value of $\mathrm{pH}$ is 7 .The best degradation rate of cefoperazone antibiotic wastewater was $95.1 \%$

\section{Acknowledgements}

This work was financially supported by the Natural Science Foundation of Heilongjiang Province NO.B2015025.

\section{References}

[1]Li Shizhong、 Li Xiaoyun、Wang Diaozuo, et ai, Membrane(RO-UF) filtration for antibiotic wastewater treatment and recovery of antibiotic, sep Purif technol, 2014, 34 (9): 109 114 [2]Konstantinou I K, Albanis T A. Photocatalytic transformation of pesticides in aqueous titanium dioxide suspensions using ar- tificial and solar light: intermediates and degradation pathways [J]. Applied Catalysis B-Environmental, 2003, 42: 319-335

[3]Marta I L, Heterogeneous photocalysis and transition metal ions in photocatalytic systems[J] Applied catalysis, 1999, 23: 89 114

[4]Cheung S T C, Fung A K M , Lam M H W, Visible photpsensitization of $\mathrm{TiO}_{2}$-photodegradation of $\mathrm{CCl}_{4}$ in aqueous mwdium[J], Chemosphere, 1998, 36: 2461 2473 